\title{
Benefits of Polydopamine as Particle/Matrix Interface in Polylactide/PD-BaSO 4 Scaffolds
}

\author{
Naroa Sadaba ${ }^{1}$, Aitor Larrañaga ${ }^{1,2}$, Gemma Orpella-Aceret ${ }^{2}$, Ana F. Bettencourt ${ }^{3}$,

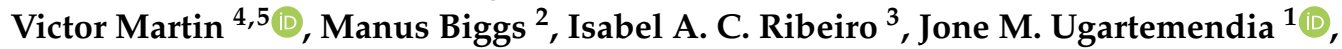 \\ Jose-Ramon Sarasua ${ }^{1}$ iD and Ester Zuza ${ }^{1, * \mathbb{D}}$ \\ 1 Department of Mining-Metallurgy Engineering and Materials Science, School of Engineering EIB 1, \\ University of the Basque Country (UPV/EHU) and Polymat, 48013 Bilbao, Spain; \\ naroasadaba89@gmail.com (N.S.); aitor.larranagae@ehu.eus (A.L.); jone.munoz@ehu.eus (J.M.U.); \\ jr.sarasua@ehu.eus (J.-R.S.) \\ 2 Center for Research in Medical Devices (CÚRAM), National University of Ireland (NUIG), Newcastle Road, \\ H91 W2TY Galway, Ireland; gemma.orpella@gmail.com (G.O.-A.); manus.biggs@nuigalway.ie (M.B.) \\ 3 Research Institute for Medicines (iMed.ULisboa), Faculdade de Farmácia, Universidade de Lisboa, Avenida \\ Prof. Gama Pinto, 1649-003 Lisboa, Portugal; asimao@ff.ulisboa.pt (A.F.B.); ribeiroi@campus.ul.pt (I.A.C.R.) \\ 4 Laboratory for Bone Metabolism and Regeneration, Faculty of Dental Medicine, U. Porto Rua Dr. Manuel \\ Pereira da Silva, 4200-393 Porto, Portugal; victorzmartin@gmail.com \\ 5 Portugal/LAQV/REQUIMTE, U. Porto, 4160-007 Porto, Portugal \\ * Correspondence: ester.zuza@ehu.eus
}

Received: 30 June 2020; Accepted: 28 July 2020; Published: 31 July 2020

check for updates

\begin{abstract}
This work reports the versatility of polydopamine (PD) when applied as a particle coating in a composite of polylactide (PLA). Polydopamine was observed to increase the particle-matrix interface strength and facilitate the adsorption of drugs to the material surface. Here, barium sulfate radiopaque particles were functionalized with polydopamine and integrated into a polylactide matrix, leading to the formulation of a biodegradable and X-ray opaque material with enhanced mechanical properties. Polydopamine functionalized barium sulfate particles also facilitated the adsorption and release of the antibiotic levofloxacin. Analysis of the antibacterial capacity of these composites and the metabolic activity and proliferation of human dermal fibroblasts in vitro demonstrated that these materials are non-cytotoxic and can be 3D printed to formulate complex biocompatible materials for bone fixation devices.
\end{abstract}

Keywords: biodegradable; composite; polylactide; barium sulfate; polydopamine; melt processing; template; 3D-printing; scaffolds; antibiotic; levofloxacin

\section{Introduction}

Polylactides are biodegradable polymers with great potential for the reconstruction of damaged tissues [1]. As is well known polylactide can be either semicrystalline (poly-L-lactide and poly-D-lactide (PLLA/PDLA)) or fully amorphous (poly-D,L-lactide (PDLLA)). For reconstruction of hard tissue stiff and strong PLLA or PDLA is preferred. Having a glass transition temperature around $60^{\circ} \mathrm{C}$, at body temperature semicrystalline PLA will be in glassy state (vs. elastomeric) and being crystalline at the same it will fulfil the requirements of a high stiffness and strength that a polymeric biomaterial requires for bone reconstruction in the form of fixation devices of small size [2]. Shortcomings to the use of PLA in bone reconstruction as opposed to e.g., metals (e.g., stainless steels or titanium alloys), include transparency to X-ray and mechanical brittleness [3,4]. However, high mass element containing fillers may be added to PLA to obtain radiopaque composites and improve its mechanical properties. Barium 
sulfate $\left(\mathrm{BaSO}_{4}\right)[5-7]$, ferrous oxide $\left(\mathrm{Fe}_{3} \mathrm{O}_{4}\right)[8]$ and bismuth oxide $[9,10]$ have been previously reported as radiopaque composite additives.

Inorganic particulate reinforcements can enhance the mechanical properties of polymers and confer additional filler-specific properties to the matrix [11]. It is also well known that the enhancement of strength related mechanical properties (elastic modulus, resistance to yield and ultimate stress) is much more noticeable with continuous fiber composites [12], however continuous fiber formulations do not lend themselves well to free-form manufacturing techniques such as extrusion, injection molding or, as is the case, 3D printing [13-15]. Particularly, 3D printing is progressing very rapidly as an advanced manufacturing technique also for particulate composites. In this domain, there are also considerable achievements in the development of drug delivery systems. Therefore, in this work we selected a 3D printable system based on a $\mathrm{BaSO}_{4}$ particulate and PLA composites with an antimicrobial drug incorporation for the potential use in fixation devices for bone tissue regeneration.

Polydopamine is a newfangled nature inspired adhesive normally used for immobilization on materials surfaces of small molecules as drugs and proteins for biomedical use [16]. In addition, it has been used for improving the thermal stability of composites [17]. In most cases promoted by its biomimetic adhesivity [18], polydopamine has been used to confer anchoring sites for biologically active molecules as drugs and proteins, as nanocapsules or nanocarriers $[19,20]$. Nevertheless, the main use of polydopamine is as substrate coating due to its ability and efficiency for conjugation with bioactive molecules as growth factors [21] and drugs [22]. Zhang et al. immobilize bone morphogenic protein 2 (BMP-2) and insulin-like growth factor 1 (IGF-1) on polydopamine coated scaffold, reducing the burst release of the factors and endowing long-term osteoconductivity [21]. Furthermore, titanium nanotubes have been coated with polydopamine to adsorb dexamethasone sodium phosphate, an anti-inflammatory and modulator of osteogenic differentiation, leading to slow, sustained and controlled drug release [22]. However, few publications have reported the use of polydopamine in polymer matrix composites reinforced with inorganic and radiopaque compounds. Almost all the publications referred to composites focus their research on dispersion and biocompatibility, for example, on boron nitride nanotubes [23], bioglass in polylactides [17] and multi-walled carbon nanotubes (MWCNT) in polyurethanes (PU) [24]. Few works have reported changes in mechanical properties of polymer composites due to polydopamine coating of the inorganic phase, one of them is that on polylactide reinforced by polydopamine functionalized halloysite nanotubes [25].

The aim of this work is to study a novel polymeric biodegradable composite system having potential for use as a biodegradable polymeric fixation template applicable to bone reconstruction. In this sense a novel composite system is studied and developed including features of radiopacity (RO) [26], mechanical toughness [3,5,11,12] and antimicrobial properties for prevention of biofilm formation [27]. In this aim, barium sulfate particles were functionalized with polydopamine and incorporated into a PLA matrix to obtain scaffolds by 3D-printing. It will be proved that this composites presents $\mathrm{X}$-ray visibility and enhanced mechanical properties (stiffness, strength, ductility and toughness) through the promotion of new deformation mechanisms caused by proper particle size and specific interactions at the fiber/matrix interfaces leading to good adhesion and improved mechanical performance. The incorporation of polydopamine to the systems presents additional benefits since provides specific sites for biologically active molecules that can be incorporated to the polymeric scaffolds leading to improvements in biocompatibility and other requirements for specific tissue engineering in situ.

\section{Results and Discussion}

\subsection{Improvements in the Mechanical Properties by Incorporation of Polydopamine Coated $\mathrm{BaSO}_{4}$ Particles into PLA}

The tensile stress-strain curves and mechanical properties of neat polylactide and its composites (PLA/PD-BaSO ${ }_{4}$ ) were determined by tensile testing. Neat PLA, not reaching a yield point, showed typical brittle behavior, exhibiting around $6 \%$ of elongation before failure and $60 \mathrm{MPa}$ of tensile strength. 
In contrast, $\mathrm{PLA} / \mathrm{PD}-\mathrm{BaSO}_{4}$ composites showed, for all $\mathrm{PD}-\mathrm{BaSO}_{4}$ amounts studied, a clear yield point and an extended ductile behavior with a dramatic increase in elongation at break (supporting information S1). This is accompanied with a moderate increase in the elastic modulus. As identified in our previous works with $\mathrm{PLA} / \mathrm{BaSO}_{4}$ composites [3,5], the plastic deformation in composites occurs because the rigid particles act as stress concentrators and, after particles debonding from the matrix and being of a $0.7-1.9 \mu \mathrm{m}$ size [28], activate, at a point of applied stress, crazing and shear yielding deformation mechanisms. Since polydopamine covered particles ( $\left.\mathrm{PD}-\mathrm{BaSO}_{4}\right)$ present $1.25 \mu \mathrm{m}$ size and interactions with the matrix through the polydopamine interface, in these composites, increases in all mechanical properties (elastic modulus, strength, ductility and toughness) are achieved [29].

Table 1 shows the tensile mechanical properties of PLA/PD-BaSO 4 composites. As can be observed, up to a $2 \mathrm{wt} . \% \mathrm{BaSO}_{4}$ content in composites, Young's modulus, ductility and toughness improvements can be observed. Further, if these results are to be compared with those of $\mathrm{PLA} / \mathrm{BaSO}_{4}$, the non PD functionalized composite counterparts, enhancements in stiffness and strength together with ductility and toughness can be noticed in the former. Please also note that a huge $>2300 \%$ increase in elongation at break are determined in these novel composite formulations in regard to neat PLA, which brings about a dramatic improvement in toughness. This is attributable to specific interactions stablished between the ester groups of polylactide and the alcohol groups of polydopamine coating of the particles surface $[18,30]$ bringing about a stronger fiber/matrix interface. It is also noticeable that a $30 \%$ increase in the elongation at break is obtained in $\mathrm{PD}$ coated $\mathrm{BaSO}_{4}$ PLA composites in regard to the composites without polydopamine coating [3]. Finally, beyond the $2 \mathrm{wt} . \%$ particle composition, a slight general decrease in mechanical properties are noticeable, suggesting the existence of particle aggregates and bundles beyond this point.

Table 1. Mechanical properties of neat polylactide (PLA) and PLA/polydopamine-barium sulfate $\left(\mathrm{PD}-\mathrm{BaSO}_{4}\right)$ composites with respect to wt.\% of $\mathrm{PD}-\mathrm{BaSO}_{4} . \sigma_{\mathrm{y}}$ : yield stress, E: Young's modulus, $\sigma_{\mathrm{b}}$ : stress at break, $\varepsilon_{\mathrm{b}}$ elongation at break and TT: tensile toughness.

\begin{tabular}{cccccc}
\hline PD-BaSO $_{\mathbf{4}}$ (wt.\%) & $\mathbf{E}(\mathbf{M P a})$ & $\boldsymbol{\sigma}_{\mathbf{y}} \mathbf{( M P a )}$ & $\boldsymbol{\sigma}_{\mathbf{r}}(\mathbf{M P a})$ & $\varepsilon_{\mathbf{b}} \mathbf{( \% )}$ & $\mathbf{T T}\left(\mathbf{J} / \mathbf{m}^{\mathbf{3}}\right)$ \\
\hline 0 & $1243 \pm 96$ & - & $67.1 \pm 0.5$ & $9.2 \pm 0.5$ & $3.8 \pm 0.6$ \\
0.5 & $1309 \pm 51$ & $78.7 \pm 0.4$ & $56.3 \pm 5.4$ & $132.2 \pm 13.1$ & $67.5 \pm 6.1$ \\
1 & $1396 \pm 109$ & $77.7 \pm 0.8$ & $56.0 \pm 4.8$ & $146.3 \pm 9.8$ & $73.6 \pm 4.6$ \\
2 & $1417 \pm 86$ & $78.4 \pm 1.7$ & $62.5 \pm 5.2$ & $182.2 \pm 5.9$ & $95.1 \pm 1.7$ \\
5 & $1415 \pm 49$ & $75.7 \pm 0.6$ & $57.6 \pm 5.8$ & $171.9 \pm 2.9$ & $85.9 \pm 0.8$ \\
10 & $1350 \pm 124$ & $74.1 \pm 0.8$ & $55.3 \pm 4.3$ & $154.6 \pm 8.6$ & $76.2 \pm 2.8$ \\
\hline
\end{tabular}

Figure 1 represents the break surface of the PLA/PD-BaSO 2 wt.\% composite. The SEM image corroborates the ductile and tough behavior of the PLA containing $2 \mathrm{wt} . \%$ barium sulfate PD-coated particles with values provided in Table 1 . A high level of dispersion of PD coated particles (indicated with white and straight arrows) within the PLA matrix can be observed. In the pictures, ductile-deformed threads of PLA matrix appear too, thinner than a micrometer in diameter. This means that the matrix has been stretched during the tensile test beyond the yield point leaving long fibers (red dot-line arrows). Therefore, radiopaque $\mathrm{PD}^{-\mathrm{BaSO}_{4}}$ particles were able to act as fixed points that under the external applied stress assisting the PLA matrix to develop specific ductile deformation mechanisms. 


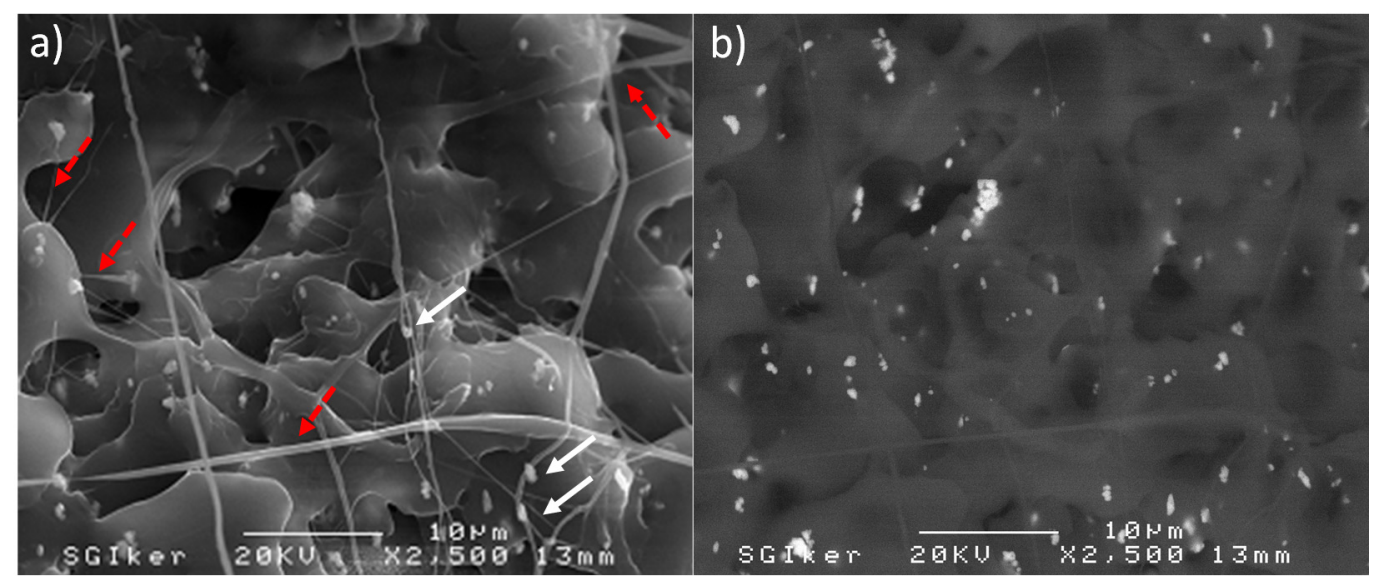

Figure 1. SEM image of PLA/PD-BaSO 2 wt.\% of filler composite obtained with dispersion of (a) secondary electrons and (b) backscattered electrons.

It is also remarkable that the values obtained for the $2 \mathrm{wt} . \%$ and $10 \mathrm{wt} . \%$ composites do not differ much from each other. However, radiopacity values, as expected, show a significant increase with the increasing amount of $\mathrm{PD}^{-B_{3 S O}} 4$ in composites (Figures S3) and particularly in the $10 \mathrm{wt} . \%$ composite. Consequently, it was concluded that among all compositions studied the $10 \mathrm{wt} \% \mathrm{PLA} / \mathrm{PD}-\mathrm{BaSO}_{4}$ composite presents the optimal properties (Figures S1 and S3) and hence an additional analysis is conducted for this composite.

The mechanical properties of the 3D printed scaffolds are also analyzed. Details of the scaffolds geometry design can be seen in Figure S4. In this case, mechanical properties were measured in compression to mimic the working conditions of the device. Non-reinforced polylactide (as reference) and the $10 \mathrm{wt} . \%$ PLA/PD-BaSO 4 scaffolds with $55 \%$ of porosity have been tested.

Figure 2 shows the stress-strain curve's behavior under compression of neat PLA scaffolds and those of its $10 \mathrm{wt} . \%$ PLA/PD-BaSO 4 composite counterpart. As can be observed the 3D printed PLA and $\mathrm{PLA} / \mathrm{PD}-\mathrm{BaSO}_{4}$ scaffolds do show different regimes and each regime corresponds to a specific mechanism of a porous structured material, in agreement with bibliography. In the first stage (region I), the walls contribute to the resistance of the scaffolds under compressive load, which results in an elastic response region at initial loads and corresponding strains. In the second stage (II), the pores collapse by buckling of the walls (barreling effect). The third stage (III) is featured by a large increase in stress over strain which may be explained by the fact that scaffolds are now compressed to a size that the scaffold becomes denser and furthermore more strain resistant to the applied load [31-33]. Despite the fact that both scaffolds have the same porosity (55\%), in Figure 2 the neat PLA behaved like a more rigid structure [34], while PLA/PD-BaSO ${ }_{4}$ shows again a flexible and softer behavior. Therefore, it can be concluded that the particles confer flexibility to the scaffolds in compression tests. 


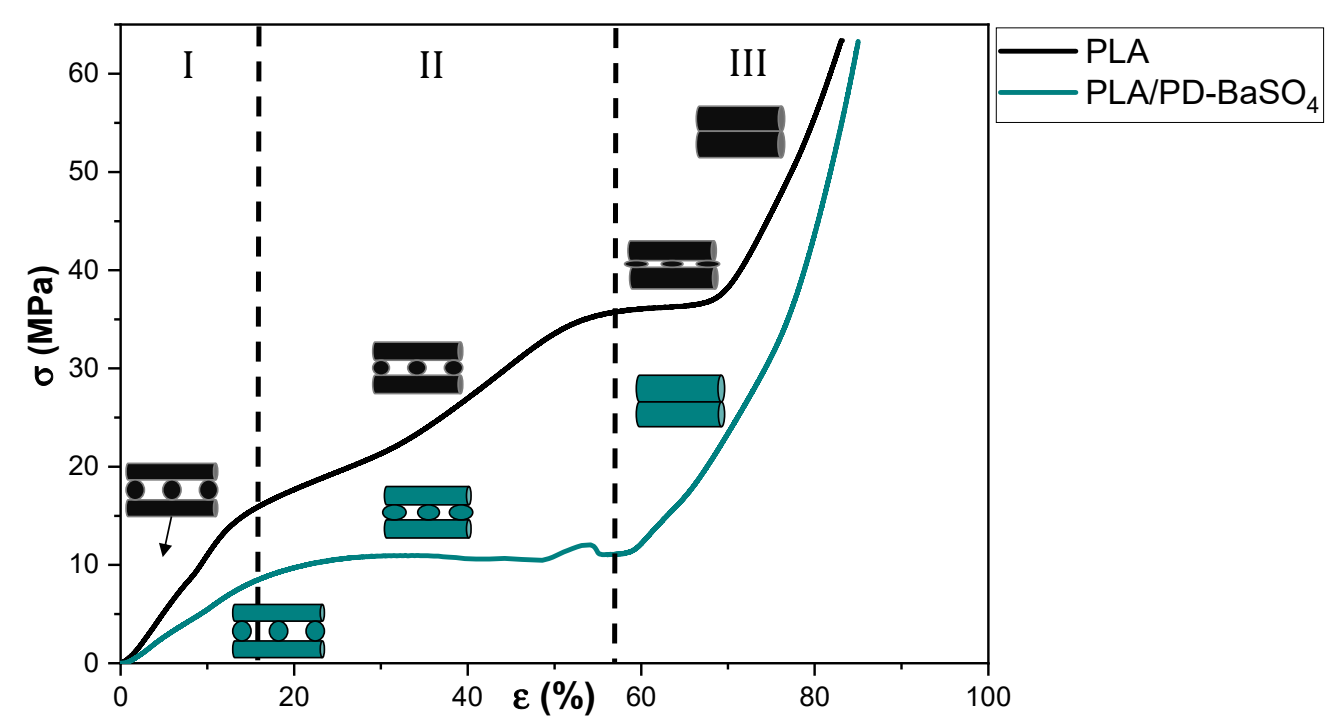

Figure 2. Compression stress $(\sigma)$-strain $(\varepsilon)$ curves of scaffolds for neat polylactide (PLA) and scaffolds for composite of polylactide and coated with polydopamine barium sulfate particles (PLA/PD-BaSO $\left.{ }_{4}\right)$ 10 wt. $\%$.

\subsection{Biocompatibility Assessment}

In vitro compatibility studies were performed to determine the possible toxicity of $\mathrm{BaSO}_{4}$ and $\mathrm{PD}_{-} \mathrm{BaSO}_{4}$ particles and their resulting PLA composites using Human dermal fibroblasts (HDFs) as a basic toxicity test. Figure 3 shows the metabolic activity of Human dermal fibroblasts (HDFs) in the presence of 10, 50, 100 or $500 \mu \mathrm{g} / \mathrm{mL}$ of $\mathrm{BaSO}_{4}$ or $\mathrm{PD}^{-\mathrm{BaSO}_{4}}$ particles. The metabolic activity displayed in this figure was normalized at each time-point with respect to the metabolic activity of HDFs seeded in the absence of particles, which was used as a control. The presence of $\mathrm{BaSO}_{4}$ and $\mathrm{PD}-\mathrm{BaSO}_{4}$ particles slightly reduced the metabolic activity of HDFs with respect to the control. However, in all the cases, the metabolic activity was higher than $80 \%$, demonstrating that HDFs were able to maintain a normal metabolic activity in the presence of particles (see also Supplementary Materials Figure S5). At day 1 , the metabolic activity of HDFs seeded with 10, 50, 100 and $500 \mu \mathrm{g} / \mathrm{mL}$ of $\mathrm{BaSO}_{4}$ particles was, 95, 94, 90 and $90 \%$, respectively, relative to that of the control. In the case of HDFs seeded with 10, 50, 100 and

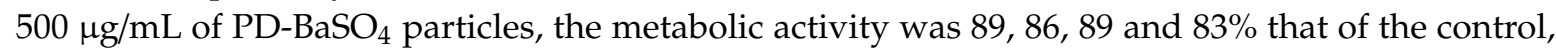
respectively. At day 3, the metabolic activity of those cells seeded with 10 or $50 \mu \mathrm{g} / \mathrm{mL}$ of $\mathrm{BaSO}_{4}$ particles, as well as $10 \mu \mathrm{g} / \mathrm{mL}$ of $\mathrm{PD}^{-B_{a S O}} 4$ particles was not significantly different from the metabolic activity of the control. At this day, the metabolic activity in all the cases was higher than $90 \%$, suggesting a negligible effect of the particles in the metabolic activity of HDFs. Additionally, cells observed under an inverted microscope showed normal morphology and the $\mathrm{BaSO}_{4}$ and $\mathrm{PD}^{-\mathrm{BaSO}_{4}}$ particles seemed to be internalized by cells and located around the nuclei (Supplementary Materials Figure S6). 


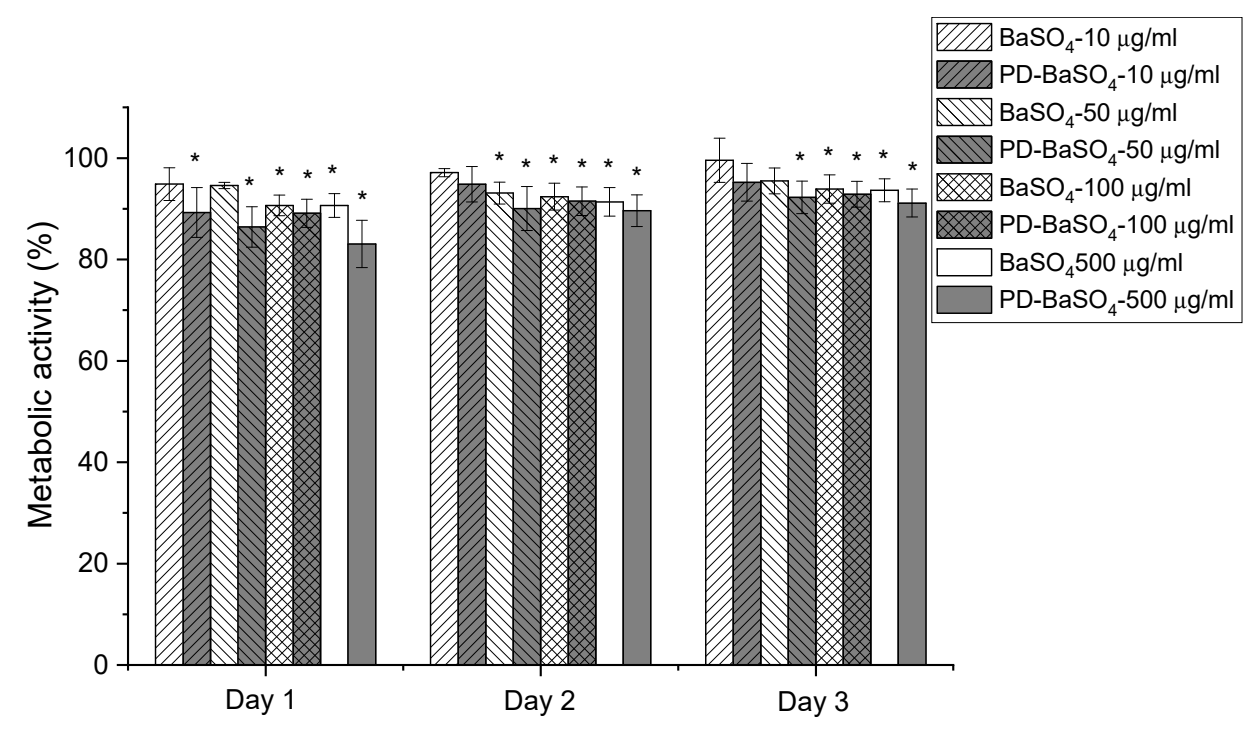

Figure 3. Metabolic activity of Human dermal fibroblasts (HDFs) seeded in the presence of 10, 50, 100 or $500 \mu \mathrm{g} / \mathrm{mL}$ of barium sulfate particles $\left(\mathrm{BaSO}_{4}\right)$ or barium sulfate particles coated with polydopamine $\left(\mathrm{PD}-\mathrm{BaSO}_{4}\right)$. Asterisks indicate significant differences $(p<0.05)$ with respect to the control.

Figure 4 shows metabolic activity of cells seeded in PLA, PLA/BaSO $4, \mathrm{PLA} / \mathrm{PD}-\mathrm{BaSO}_{4}$ with $10 \mathrm{wt} . \%$ of filler composites and control tissue culture plastic (TCP). The metabolic activity was normalized at each time-point with the metabolic activity of HDFs seeded onto the TCP, which was used as a control. Except for cells seeded on PLA after 3 days of culture (see Table S1), no significant differences were observed in the metabolic activity of HDFs with respect to the control, indicating normal metabolic activity of cells seeded on the composites developed in this work.

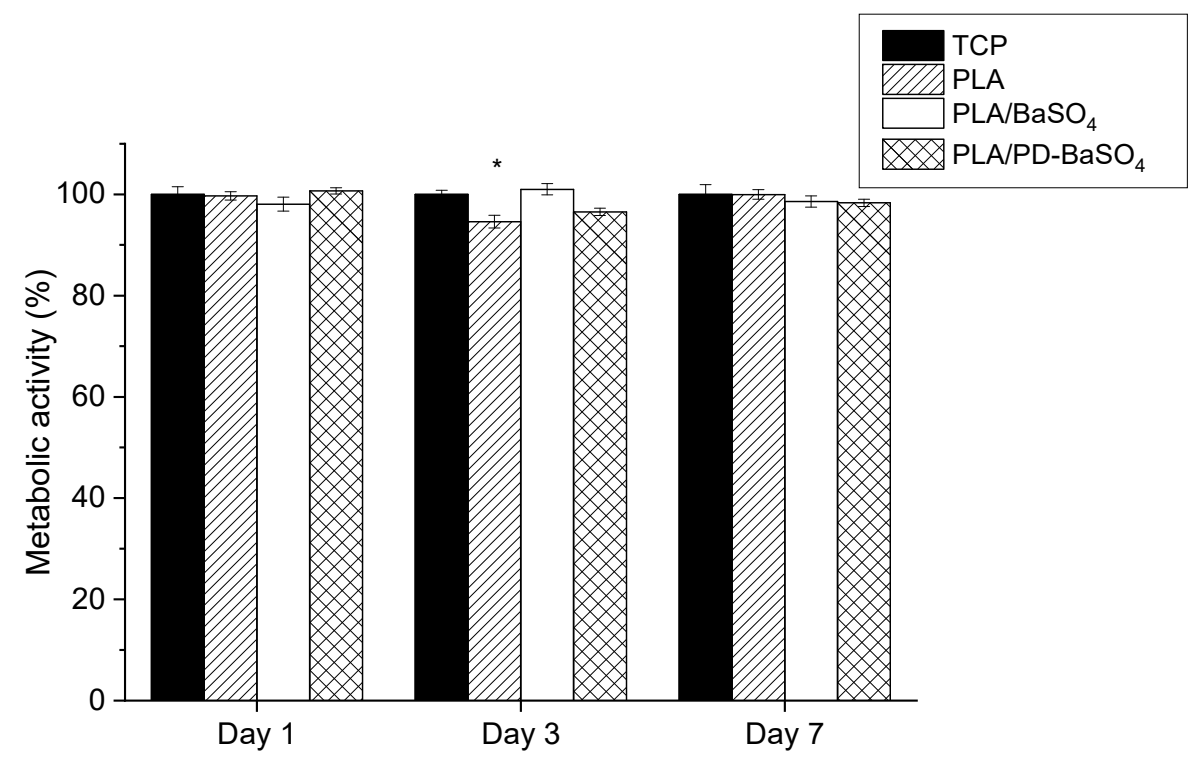

Figure 4. Metabolic activity of Human dermal fibroblasts HDFs seeded on polylactide (PLA), composite of polylactide and barium sulfate particles $\left(\mathrm{PLA} / \mathrm{BaSO}_{4}\right)$ and composite of polylactide and coated with polydopamine barium sulfate particles (PLA/PD-BaSO 4 ) with respect to the control at day 1,3 and 7. Asterisks indicate significant differences $(p<0.05)$ with respect to the cells seeded on tissue culture plastic (TCP).

The proliferation of $\mathrm{HDFs}$ on PLA, $\mathrm{PLA} / \mathrm{BaSO}_{4}$ and PLA/PD-BaSO 4 composites was evaluated via DNA quantification. As can be seen in Figure 5, DNA content increased over culture time in all 
experimental and control conditions. Accordingly, significant differences were observed between DNA content observed at day 7 and that observed at day 1 for all the samples studied. For example, the calculated proliferation rates between day 1 and day 7 were 1.6, 3.2 and 2.4 for PLA, PLA/BaSO 4 and PLA/PD-BaSO 4 , respectively. The metabolic activity and proliferation results demonstrate that the materials employed in this work are not cytotoxic and can provide a cytocompatibility substrate for cells to attach and proliferate. A higher proliferation of $\mathrm{HDFs}$ was observed in $\mathrm{PLA} / \mathrm{BaSO}_{4}$ or $\mathrm{PLA} / \mathrm{PD}-\mathrm{BaSO}_{4}$ composites with respect to pristine PLA samples. Is hypothesized that this higher proliferation rate may be associated to surface characteristic of the samples, such as roughness or hydrophilicity $[35,36]$

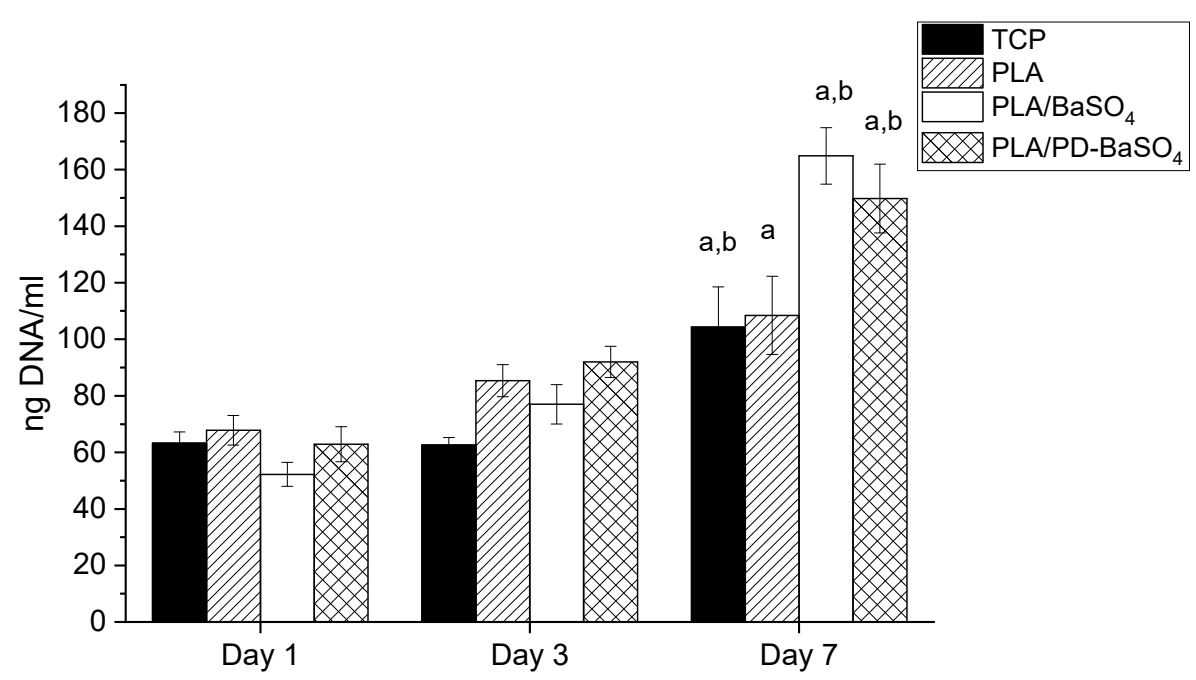

Figure 5. Proliferation of Human dermal fibroblasts HDFs seeded polylactide (PLA), composite of polylactide and barium sulfate particles $\left(\mathrm{PLA} / \mathrm{BaSO}_{4}\right)$ and composite of polylactide and coated with polydopamine barium sulfate particles (PLA/PD-BaSO ${ }_{4}$ ) a and $\mathrm{b}$ indicate significant differences $(p<0.05)$ with respect to day 1 and day 3 , respectively.

Concurrently, PD coating of $\mathrm{BaSO}_{4}$ particles introduced binding sites for biologically active molecules such as proteins or drugs, increasing the use of this composite in second-generation devices for biomedical applications.

\subsection{Adsorption/Release Test in 3D Printed Scaffolds}

Following confirmation of cytocompatibility, the potential for antibiotic delivery with 3D printed scaffolds of PLA/PD-BaSO 4 was evaluated in vitro, with the aim of preventing an infection due to the insertion surgery (open wound) and the consequent rejection of the device [37]. To this end, levofloxacin was incorporated into the material via $\mathrm{PD}-\mathrm{BaSO}_{4}$ particle functionalization as a local drug delivery system for avoiding the oral administration common in this kind of surgeries. Levofloxacin is used for fighting and preventing osteomyelitis, since it is a fluoroquinolone with anti-staphylococcal activity in osteoarticular tissues [38].

Here, in order to compare the levofloxacin loading efficiency of the developed composites a polydopamine coated neat PLA sample (termed PD-PLA) is introduced. The release was performed at $\mathrm{pH} 5$ to simulate the state of infection and at body temperature of $37^{\circ} \mathrm{C}$.

Figure 6 shows a non-detectable release of PLA, this is because the scaffolds have been previously washed, therefore there was a very low level of drug in PLA scaffolds, reflecting also that PLA does not adsorb the antibiotic and consequently does not release it either. Furthermore, in the case of PD-PLA a burst release was observed during the first $24 \mathrm{~h}$ where almost $80 \%$ of levofloxacin eluted. The remaining amount of drug $(20 \%)$ was eluted in 4 days. This type of release profile is adequate in the context of an infection, since at the beginning a high rate of drug release is desirable followed by 
a slower drug release. When the PLA/PD-BaSO 4 was analyzed, a more moderate burst release was observed where almost $60 \%$ of levofloxacin eluted and later, during the next 3 days the $30 \%$ of drug was eluted while the last two days shows a very slow release with an $8 \%$ release (see Figure S6). In the end the PLA only releases $0.43 \mu \mathrm{g} / \mathrm{mL}$ due to the drug that is trapped in the holes. While PD-PLA was the one with the highest amount of drug released, $3.12 \mu \mathrm{g} / \mathrm{mL}$, the PLA/PD-BaSO ${ }_{4}$ composite drug released a $2.4 \mu \mathrm{g} / \mathrm{mL}$.

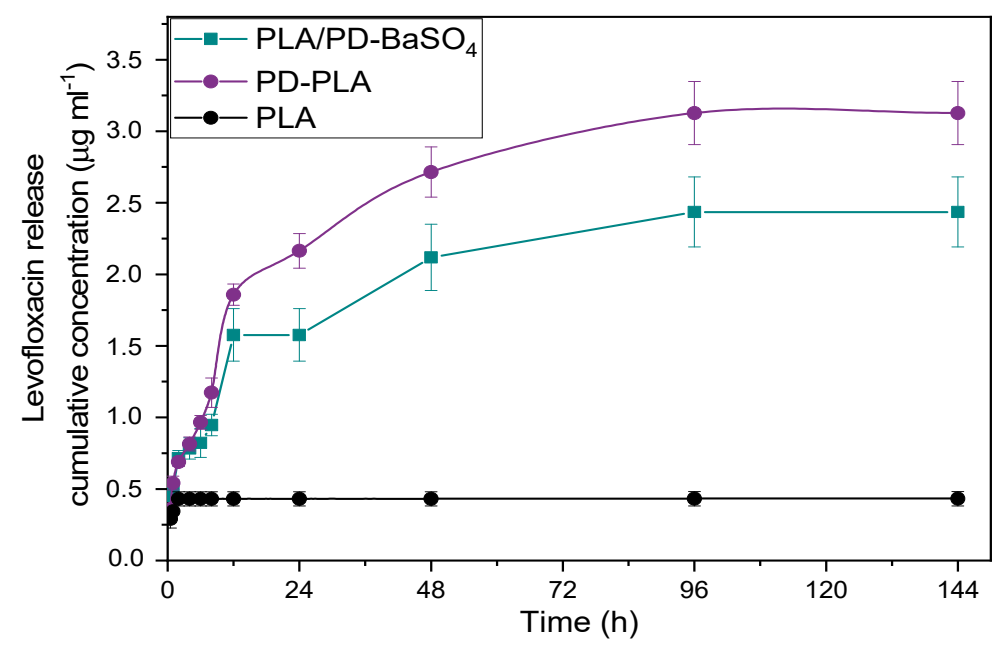

Figure 6. Release profiles over time of levofloxacin in neat PLA, polydopamine coated neat PLA (PD-PLA) and PLA/PD-BaSO 4 .

These release results in global show that PD-PLA and PLA/PD-BaSO 4 display potential antimicrobial properties. Comparing these two materials, the release profile of $\mathrm{PLA} / \mathrm{PD}-\mathrm{BaSO}_{4}$ composites was more interesting as it generated a second elution stage with greater release, $40 \%$ versus $20 \%$ in PD-PLA. It is remarked finally that these scaffolds were immersed in trizma buffer ( $\mathrm{pH} 10)$ prior to analysis so the results of Figure 6 correspond to bound levofloxacin after adsorption.

\subsection{Antimicrobial Activity of 3D PLA/PD-BaSO ${ }_{4}$ Scaffolds with Levofloxacin}

To analyze the antibiotic efficacy of the 3D printed scaffolds the Agar Disk Diffusion tests against Staphylococcus aureus (S. aureus) were carried out. S. aureus was chosen because in bone infections is one of the most important pathogens due to its ability to adhere and form biofilms when in contact with tissue [38]. Figure 7 shows the Agar disk diffusion test corresponding to 3D printed scaffolds of $\mathrm{PLA} / \mathrm{PD}-\mathrm{BaSO}_{4}$ with levofloxacin, $\mathrm{PLA} / \mathrm{PD}-\mathrm{BaSO}_{4}$ scaffold as a negative control without levofloxacin and the disk of levofloxacin $(5 \mu \mathrm{g})$ as a positive control. Cicuéndez et al. calculated that the minimum inhibitory concentration (MIC) of levofloxacin has a value of $0.06 \mu \mathrm{g} / \mathrm{mL}$ [39]. As observed in the release assay (Figure 6), these scaffolds release larger amounts of the drug.

Analyzing the Agar Disk Diffusion tests is observed that PLA/PD-BaSO 4 scaffolds with levofloxacin effectively inhibit bacterial growth, being the inhibition zone diameters of $38 \pm 4 \mathrm{~mm}$ (Figure 7a), while the positive control ( $5 \mu \mathrm{g}$ of Levofloxacin) exhibited a diameter average $28 \pm 0 \mathrm{~mm}$ (Figure $7 \mathrm{c}$ ). No inhibition zone could be observed for the sample without levofloxacin, $\mathrm{PLA} / \mathrm{PD}-\mathrm{BaSO}_{4}$ (negative control, Figure $7 \mathrm{~b}$ ). It should be noted here that the scaffolds were washed after the drug adsorption, therefore the effective inhibition of bacterial growth is attributed to the amount of levofloxacin bound to polydopamine coating of the particles and not to an unspecified content of drug that could remain in the scaffold holds. This would still lead to a higher inhibition zone. 


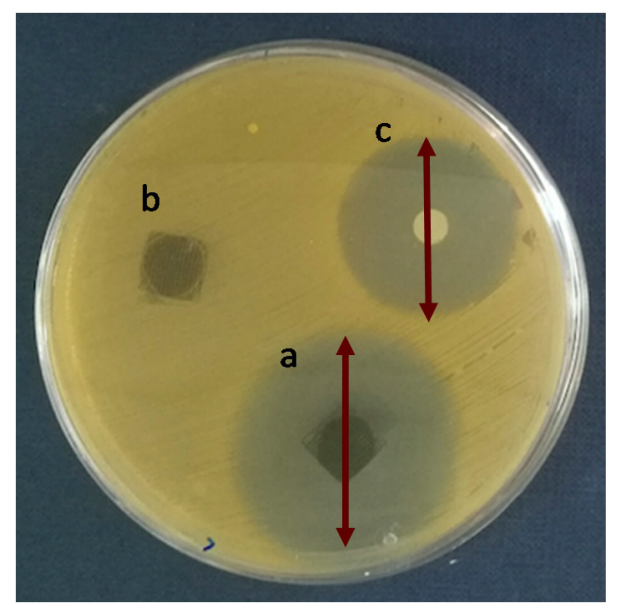

Figure 7. Agar disk diffusion tests: (a) PLA/PD-BaSO 4 with levofloxacin, (b) $\mathrm{PLA} / \mathrm{PD}-\mathrm{BaSO}_{4}$ negative control (no levofloxacin) and (c) levofloxacin disk $(5 \mu \mathrm{g})$ as a positive control.

From Agar diffusion tests can be concluded that the polydopamine coating method of $\mathrm{BaSO}_{4}$ particles used for drug tethering within the PLA composites is effective and facilitates the release of the drug inhibiting the $S$. aureus growth. The described method is simple and allows the addition of the antibiotic after a 3D printing process of scaffolds. This fact has two advantages since the drug is not processed with the scaffold avoiding either the contact with organic solvents nor high processing temperatures that could degrade the molecules, and, on the other hand, the adsorption of the medicament by a scaffold or implant can be done when clinically necessary, in situ.

\section{Materials and Methods}

\subsection{Materials}

Poly (D-lactide) homopolymer (100,000 $\mathrm{gmol}^{-1}$ ) (PLA) was supplied by Purac-Corbion (Barcelona, Spain). Dopamine chloride, Barium sulfate $\left(\mathrm{BaSO}_{4}\right)$, phosphate buffer saline (PBS) and levofloxacin were purchased from Sigma-Aldrich (Madrid, Spain). Dulbecco's modified Eagle's medium (DMEM), fetal bovine serum (FBS), Hank's balanced salt solution (HBSS) and penicillin-streptomycin (PS) solution Human dermal fibroblasts (HDFs) were purchased from Sigma-Aldrich (Arklow, Ireland). Quant-ITTM PicoGreen ${ }^{\circledR}$ dsDNA kit was from Invitrogen (Dublin, Ireland) and AlamarBlue ${ }^{\circledR}$ is from ThermoFisher Scientific (Dublin, Ireland).

\subsection{Coating with Polydopamine and Blending}

Coating of particles covered with polydopamine (PD) to obtain $\mathrm{PD}^{-\mathrm{BaSO}_{4}}$ were obtained as in our previous article using basic $\mathrm{pH} 8.5$ for $24 \mathrm{~h}$ followed by filtration and drying in a vacuum oven overnight [17]. The same coating method was used for the PD-PLA scaffolds. The size of the particles was measured by HORIBA Laser Scattering Particle Size Distribution Analyzer LA-350 (Horiba, Kyoto, Japan).

Polylactide samples were filled with $0.5,1,2,5$ and $10 \mathrm{wt} . \%$ of $\mathrm{PD}-\mathrm{BaSO}_{4} \cdot \mathrm{PD}-\mathrm{BaSO}_{4}$ particles and neat polylactide (PLA) were melt mixed in a DSM Xplore micro-compounder (Xplore Instruments, Sittard, The Netherlands) at $200{ }^{\circ} \mathrm{C}$ and $150 \mathrm{rpm}$ during $2 \mathrm{~min}$ and then conformed by injection molding. The mold was pre-heated at $45^{\circ} \mathrm{C}$ and the injection temperature was $200{ }^{\circ} \mathrm{C}$. Gel Permeation Chromatography (GPC) tests were carried out before and after blending process to check that the matrix is not degraded (see Figure S7). The weight average molecular mass (Mw) and dispersity (D) of PLA pellets before processing were respectively $\mathrm{Mw}=183758 \mathrm{gmol}^{-1}$ and $\mathrm{D}=1.8$ whereas, after processing in a PLA/BaSO 4 composite, the values obtained for PLA were $\mathrm{Mw}=174980 \mathrm{gmol}^{-1}$ and $\mathrm{I}=1.8$. 
Scanning Electron Microscopy (SEM) and Transmission Electron Microscopy (TEM) were used to observe both the degree of dispersion of the particles inside of the polymer matrix and the break surfaces.

\subsection{D Printing of Radiopaque Scaffolds}

Scaffold fabrication was carried out in a 3D-Bioplotter from Envision TEC. Scaffolding 3D model was designed with Computer Aided Drawing (CAD, Autodesk, San Rafael, CA, USA). The CAD model was uploaded to the Bioplotter software (version 3.0.713.1406, Envision TEC, Gladbeck, Germany), which enables slicing of the model, before 3D-printing.

Two types of scaffolds were designed: one for mechanical properties and the other for the antibiotic release tests. Cylindrical geometries having $10 \mathrm{~mm}$ diameter and $10 \mathrm{~mm}$ height were used for measuring mechanical properties in compression mode, whereas square geometries $(10 \times 10 \times$ $2 \mathrm{~mm}$ ) (length $\times$ width $\times$ height) were used for adsorption/release and Agar Diffusion tests. In both cases the pore size of the scaffolds was $500 \mu \mathrm{m}$ and it was used a plastic conic needle of $0.25 \mathrm{~mm}$ inner diameter for the printing layer dimension (Figure S8). The resulting file was uploaded to the software Visual Machines (version 2.8.126) that allows the user to input the various parameters that control the Bioprinter (Envision TEC).

Due to the specific dimensions of the feeding cartridge and the degradable nature of the polymer, the scaffolds are printed by solution. The materials (PLA and PLA/PD-BaSO ${ }_{4}$ ) were dissolved with chloroform during $48 \mathrm{~h}$, printed at $20{ }^{\circ} \mathrm{C}$. The printing conditions are shown in Table 2. Reproducibility of the PLA and PLA/PD-BaSO 4 support frames was ensured by using the same CAD model for each frame, and by the high $\mathrm{XYZ}$ axis resolution of the Bioplotter $(0.001 \mathrm{~mm})$.

Table 2. Printing conditions for neat PLA and composite PLA/PD-BaSO 4 .

\begin{tabular}{cccccc}
\hline Material & Temperature $\left({ }^{\circ} \mathbf{C}\right)$ & Pressure (Bar) & Speed(mm/s) & Post-Flow(s) & Pre-Flow(s) \\
\hline PLA & 25 & 5.0 & 3.5 & 0.11 & 0.04 \\
PLA/PD-BaSO & 25 & 4.4 & 4.1 & 0.11 & 0.01 \\
\hline
\end{tabular}

\subsection{Mechanical Properties}

Dumbbell-shaped samples for tensile tests were punched out from sheets following ISO 527-2 (ISO 527-2/5A/5). In the case of 3D-printed scaffolds, the mechanical properties under compression were obtained following ISO 604. In both testing modes the tests were performed with an Instron 5565 testing machine at $23^{\circ} \mathrm{C}$ and $50 \%$ of relative humidity (RH).

\subsection{Adsorption/Release Test}

Before starting the release test, the adsorption of levofloxacin in the scaffolds has been carried out. For that, the scaffolds were submerged in a buffer at $\mathrm{pH} 10$ with levofloxacin $(2 \mathrm{mg} / \mathrm{mL})$ [40] for $24 \mathrm{~h}$ for facilitate the adsorption. Then, the scaffolds were washed with buffer at $\mathrm{pH} 10$ and dried. The washing was done to eliminate the drug from the holes of the scaffolds, and in this way obtain the amount of drug that is absorbed by the material itself.

Levofloxacin release was evaluated using a UV-vis spectrophotometer (BMG Labtech FLUOstar Omega, Ortenberg, Germany). The band in $\lambda=287 \mathrm{~nm}$ for levofloxacin was employed to build a standard curve with known concentrations of the drug in PBS and the measurements were carried out at concentrations lower than $25 \mathrm{ppm}$. Release of levofloxacin from the scaffolds was tested in $3 \mathrm{~mL}$ of PBS at $37^{\circ} \mathrm{C}$, under mild agitation $(220 \mathrm{rpm})$ at $\mathrm{pH}$ 5. Samples were taken at the following times: $30 \mathrm{~min}, 1 \mathrm{~h}, 2 \mathrm{~h}, 4 \mathrm{~h}, 6 \mathrm{~h}, 8 \mathrm{~h}, 12 \mathrm{~h}, 24 \mathrm{~h}, 48 \mathrm{~h} 72 \mathrm{~h}, 96 \mathrm{~h}$ and $144 \mathrm{~h}$. In all materials, three independent tests were carried out. 


\subsection{Agar Disk Diffusion}

The diffusion disk agar tests for Staphylococcus aureus inoculum were performed under the Clinical and Laboratory Standards (CLSI) [40]. Briefly, few colonies of S. aureus were resuspended in Mueller Hinton Broth (Biokar Diagnostics, Pantin, France) and further diluted in order to achieve 0.5 McFarland units $\left(1 \times 10^{8} \mathrm{CFU} \mathrm{mL}^{-1}\right)$ at $600 \mathrm{~nm}$ of wavelength, using a spectrophotometer (U-2000, Hitachi, Tokyo, Japan). The inoculum was swabbed on Mueller Hinton Agar (Biokar Diagnostics) plates and the scaffolds (one without drug as a negative control) were tested, as well as $5 \mu \mathrm{g}$ of levofloxacin disk (positive control). Petri dishes were further incubated (Ultima, Revco, Thermo Scientific) at $37^{\circ} \mathrm{C}$ for $24 \mathrm{~h}$. Assays were performed in three independent experiments

\subsection{Cell Culture}

\subsubsection{Human Dermal Fibroblasts}

HDFs were grown in T75 flasks using DMEM with 10\% FBS and 1\% PS. The cells were incubated at $37^{\circ} \mathrm{C}$ in an atmosphere of $5 \% \mathrm{CO}_{2}$. The culture medium was changed every 3 days. The cells were then harvested and sub-cultured when $>90 \%$ confluence was observed.

\subsubsection{Cell Seeding}

To study the metabolic activity of $\mathrm{HDFs}$ seeded in the presence of $\mathrm{BaSO}_{4}$ or $\mathrm{PD}-\mathrm{BaSO}_{4}, \mathrm{HDFs}$ were seeded at a density of 25,000 cells $/ \mathrm{cm}^{2}$ in a 96 well tissue culture plate and incubated in $0.5 \mathrm{~mL}$ of DMEM with $10 \% \mathrm{FBS}$ and $1 \% \mathrm{PS}\left(37^{\circ} \mathrm{C}, 5 \% \mathrm{CO}_{2}\right)$. After 1 day in culture, the media was replaced by complete media containing $0,10,50,100$ or $500 \mu \mathrm{g} / \mathrm{mL}$ of $\mathrm{BaSO}_{4}$ or $\mathrm{PD}_{-} \mathrm{BaSO}_{4}$ particles that were previously autoclaved.

HDFs were also seeded on sterilized PLA, $\mathrm{PLA} / \mathrm{BaSO}_{4}$ and PLA/PD-BaSO 4 samples $(7 \mathrm{~mm}$ in diameter) at a density of 25,000 cells $/ \mathrm{cm}^{2}$ in a 48 well tissue culture plate and incubated in DMEM with $10 \% \mathrm{FBS}$ and $1 \%$ PS. First, HDFs were suspended in $40 \mu \mathrm{L}$ of culture medium, seeded onto each sample and incubated for $2 \mathrm{~h}$ to allow cell attachment $\left(37^{\circ} \mathrm{C}, 5 \% \mathrm{CO}_{2}, 95 \%\right.$ relative humidity). When cells were attached, and additional $0.5 \mathrm{~mL}$ of culture medium was added into each well. The culture medium was replaced at day 3 after seeding.

\subsubsection{Cell Viability Studies}

AlamarBlue ${ }^{\circledR}$ assay was performed to quantify the metabolic activity of HDFs in the presence of $\mathrm{BaSO}_{4}$ or $\mathrm{PD}-\mathrm{BaSO}_{4}$ particles or seeded on PLA, PLA/BaSO 4 and PLA/PD-BaSO 4 . At the selected

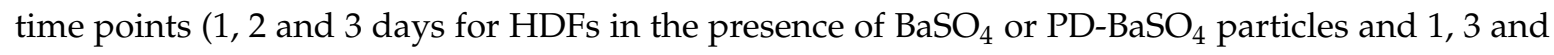
7 days for HDFs seeded on PLA, $\mathrm{PLA} / \mathrm{BaSO}_{4}$ and PLA/PD-BaSO 4 ), the cells were washed with HBSS and subsequently incubated $\left(6 \mathrm{~h}, 37^{\circ} \mathrm{C}\right.$, sheltered from light) in $0.5 \mathrm{~mL}$ of fresh culture media with AlamarBlue ${ }^{\circledR}(10 \% v / v)$. Then, $100 \mu \mathrm{L}$ of assay media was transferred to a 96 well plate, the absorbance at 550 and $595 \mathrm{~nm}$ was read on a microplate reader (Varioskan Flash, Thermo Fisher Scientific) and the percentage reduction of the dye was calculated.

To quantify the DNA amount of cells seeded on PLA, PLA/BaSO 4 and PLA/PD-BaSO ${ }_{4}$ a PicoGreen ${ }^{\circledR}$ assay was then performed on the same samples used for AlamarBlue ${ }^{\circledR}$. Cells were repeatedly frozen at $-80{ }^{\circ} \mathrm{C}$ and thawed to lyse the cells and release the entire DNA content. Finally, fluorescence was measured at $480 \mathrm{~nm}$.

\subsubsection{Statistics}

Statistical differences were analyzed using one-way analysis of variance (ANOVA) and $p$-values of $<0.05$ were considered significant. Experiments were performed in triplicate and each assay was repeated three times. 


\section{Conclusions}

In this work the mechanical brittleness associated to polylactide homopolymers is overcome via the incorporation of $\mathrm{PD}^{-B_{a S O}}$ particles into a PLA matrix. The composite materials showed enhanced stiffness, strength, ductility and toughness. This is indeed relevant since in classical polymer/inorganic composites increases in stiffness and strength usually lead to dramatic decreases of ductility and toughness.

The particulate composites studied in this work are proved to be a valid substrate for cells to attach and proliferate. In addition, coating of barium sulfate particles with polydopamine provides functional groups that can act as anchorage points for incorporation of molecules with biological activity i.e., levofloxacin which is an antibacterial drug. The benefits of $\mathrm{PD}^{-\mathrm{BaSO}_{4}}$ prove the potential of use of these PLA composites in bone reconstruction applications.

Supplementary Materials: Supplementary Materials can be found at http:/www.mdpi.com/1422-0067/21/15/ 5480/s1. Figure S1. Tensile stress-strain curves of bulk materials. Figure S2. Particle size of $\mathrm{BaSO}_{4}$ (grey) and

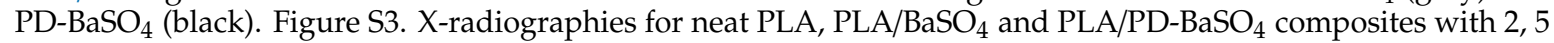
and $10 \mathrm{wt} . \%$ of $\mathrm{BaSO}_{4}$ and PD-BaSO 4 . Figure S4. PLA/PD-BaSO 4 (left) and neat PLA (right) 3D-printed cylindric scaffolds for compression tests. Figure S5. HDFs seeded in the presence of $500 \mu \mathrm{g} / \mathrm{mL}$ of $\mathrm{BaSO}_{4}$. Figure S6. Release profiles over time of levofloxacin in neat PLA, PD-PLA and PLA/PD-BaSO 4 . Figure S7. GPC refractive-index signals for PLA/PD-BaSO 4 before and after blending process at $200{ }^{\circ} \mathrm{C}$. Figure S8. The microscopy image of PLA scaffold. (a) $\times 10$ and (b) $\times 5$. Table S1. Summary of the metabolic activity of the $\mathrm{BaSO}_{4}$ and $\mathrm{PD}^{-\mathrm{BaSO}_{4}}$ particles as well as the materials PLA, PLA/ $\mathrm{BaSO}_{4}$ and PLA/PD-BaSO 4 .

Author Contributions: E.Z., A.L. and J.-R.S. developed the idea and established the conceptual framework of the research. E.Z. guided and coordinated the research. N.S. and V.M. carried out the drug delivery and antimicrobial experiments designed by A.F.B. and I.A.C.R. A.L. and G.O.-A. designed and carried out the cell experiments. J.M.U. participated also in the discussion of results. N.S., A.L., E.Z., M.B. and J.-R.S. wrote and edited the manuscript. All authors have read and agreed to the published version of the manuscript.

Funding: The work has been financially supported by the Basque Government Department of Education, Linguistic Politics and Culture for a consolidated research group project IT-927-16, the Spanish Government's MINECO MAT2016-78527-P (AEI/FEDER, UE) and EU's COST TD1305 project. N.S. received a short-term scientific mission grant (ECOST-STSM-TD1305-38384). M.B. acknowledges the Science Foundation Ireland (16/BBSRC/3317). A.B. and I.R. acknowledge the Portuguese government, Fundação para a Ciência e Tecnologia (FCT) for project UID/DTP/04138/2019 (iMed.ULisboa). N.S. thanks POLYMAT for her PhD predoctoral grant, and A.L. the Basque Government for a postdoctoral fellowship.

Acknowledgments: The authors express thanks for technical and human support provided by SGIker of UPV/EHU and European funding: European Regional Development Fund (ERDF) and European Social Fund (ESF).

Conflicts of Interest: The authors declare no conflict of interest.

\section{Abbreviations}

BMP-2

$\mathrm{PLA} / \mathrm{BaSO}_{4}$

PLA/PD-BaSO 4

CAD

DNEM

$\varepsilon_{\mathrm{r}}$

$\mathrm{Fe}_{3} \mathrm{O}_{4}$

FBS

GPC

HBSS

HDFs

IGF-1

MIC

MWCNT

PS

PBS

PD-PLA
Bone morphogenic protein 2

Composite of Polylactide and barium sulfate particles

Composite of polylactide and coated with polydopamine barium sulfate particles

Computer Aided Drawing

Dulbecco's modified Eagle's medium

Elongation at break

Ferrous Oxide

Fetal bovine serum

Gel Permeation Chromatography

Hank's balanced salt solution

Human dermal fibroblasts

Insulin growth factor 1

Minimum inhibitory concentration

Multi-walled carbon nanotubes

Penicillin-streptomycin

Phosphate buffer saline

Polylactide cover by polydopamine 


$\begin{array}{ll}\text { PD } & \text { Polydopamine } \\ \text { PU } & \text { Polyurethanes } \\ \text { RO } & \text { Radiopacity } \\ \text { RH } & \text { Relative Humidity } \\ \text { SEM } & \text { Scanning Electron Microscopy } \\ \text { S. aureus } & \text { Staphylococcus aureus } \\ \text { E } & \text { Tensile Modulus } \\ \sigma_{\mathrm{r}} & \text { Tensile strength } \\ \text { TT } & \text { Tensile toughness } \\ \sigma_{\mathrm{y}} & \text { Tensile Yield } \\ \text { TCP } & \text { Tissue culture plastic } \\ \text { TEM } & \text { Transmission Electron Microscopy } \\ \text { wt. } \% & \text { Weight percent }\end{array}$

\section{References}

1. Hamad, K.; Kaseem, M.; Yang, H.W.; Deri, F.; Ko, Y.G. Properties and medical applications of polylactic acid: A review. Express Polym. Lett. 2015, 9, 435-455. [CrossRef]

2. Tajbakhsh, S.; Hajiali, F. A comprehensive study on the fabrication and properties of biocomposites of poly(lactic acid)/ceramics for bone tissue engineering. Mater. Sci. Eng. C 2017, 70, 897-912. [CrossRef]

3. Martínez De Arenaza, I.; Sadaba, N.; Larrañaga, A.; Zuza, E.; Sarasua, J.R. High toughness biodegradable radiopaque composites based on polylactide and barium sulphate. Eur. Polym. J. 2015, 73, 88-93. [CrossRef]

4. Sarasua, J.R.; Arraiza, A.L.; Balerdi, P.; Maiza, I. Crystallinity and mechanical properties of optically pure polylactides and their blends. Polym. Eng. Sci. 2005, 45, 745-753. [CrossRef]

5. Sadaba, N.; Martini, R.; Barthelat, F.; Martínez de Arenaza, I.; Larrañaga, A.; Sarasua, J.R.; Zuza, E. Understanding the toughness mechanism prompted by submicron rigid particles in polylactide/barium sulfate composites. Polym. Test. 2018, 69, 340-349. [CrossRef]

6. Grémare, A.; Guduric, V.; Bareille, R.; Heroguez, V.; Latour, S.; L’heureux, N.; Fricain, J.C.; Catros, S.; Le Nihouannen, D. Characterization of printed PLA scaffolds for bone tissue engineering. J. Biomed. Mater. Res. Part A 2018, 106, 887-894. [CrossRef] [PubMed]

7. Nuutinen, J.-P.; Clerc, C.; Törmälä, P. Mechanical properties and in vitro degradation of self-reinforced radiopaque bioresorbable polylactide fibres. J. Biomater. Sci. Polym. Ed. 2003, 14, 665-676. [CrossRef] [PubMed]

8. Chang, W.-J.; Pan, Y.-H.; Tzeng, J.-J.; Wu, T.-L.; Fong, T.-H.; Feng, S.-W.; Huang, H.-M. Development and Testing of X-Ray Imaging-Enhanced Poly-L-Lactide Bone Screws. PLoS ONE 2015, 10, e0140354. [CrossRef]

9. Noor Azman, N.Z.; Musa, N.F.L.; Nik Ab Razak, N.N.A.; Ramli, R.M.; Mustafa, I.S.; Abdul Rahman, A.; Yahaya, N.Z. Effect of Bi2O3 particle sizes and addition of starch into Bi2O3-PVA composites for X-ray shielding. Appl. Phys. A 2016, 122, 818. [CrossRef]

10. Abunahel, B.M.; Mustafa, I.S.; Noor Azman, N.Z. Characteristics of X-ray attenuation in nano-sized bismuth oxide/epoxy-polyvinyl alcohol (PVA) matrix composites. Appl. Phys. A Mater. Sci. Process. 2018, 124, 1-7. [CrossRef]

11. Zuza, E.; Meaurio, E.; Sarasua, J.-R. Biodegradable Polylactide-Based Composites. In Composites from Renewable and Sustainable Materials; InTech: Rijeka, Croatia, 2016.

12. Xiu, H.; Qi, X.; Liu, Z.; Zhou, Y.; Bai, H.; Zhang, Q.; Fu, Q. Simultaneously reinforcing and toughening of polylactide/carbon fiber composites via adding small amount of soft poly(ether)urethane. Compos. Sci. Technol. 2016, 127, 54-61. [CrossRef]

13. Wang, X.; Jiang, M.; Zhou, Z.; Gou, J.; Hui, D. 3D printing of polymer matrix composites: A review and prospective. Compos. Part B Eng. 2017, 110, 442-458. [CrossRef]

14. Parandoush, P.; Lin, D. A review on additive manufacturing of polymer-fiber composites. Compos. Struct. 2017, 182, 36-53. [CrossRef]

15. Poh, P.S.P.; Chhaya, M.P.; Wunner, F.M.; De-Juan-Pardo, E.M.; Schilling, A.F.; Schantz, J.-T.; van Griensven, M.; Hutmacher, D.W. Polylactides in additive biomanufacturing. Adv. Drug Deliv. Rev. 2016, 107, 228-246. [CrossRef] [PubMed] 
16. Liu, Y.; Ai, K.; Lu, L. Polydopamine and Its Derivative Materials: Synthesis and Promising Applications in Energy, Environmental, and Biomedical Fields. Chem. Rev. 2014, 114, 5057-5115. [CrossRef]

17. Larrañaga, A.; Ramos, D.; Amestoy, H.; Zuza, E.; Sarasua, J.-R. Coating of bioactive glass particles with mussel-inspired polydopamine as a strategy to improve the thermal stability of poly(l-lactide)/bioactive glass composites. RSC Adv. 2015, 5, 65618-65626. [CrossRef]

18. Ahn, B.K. Perspectives on Mussel-Inspired Wet Adhesion. J. Am. Chem. Soc. 2017, 139, $10166-10171$. [CrossRef]

19. Zhuang, H.; Su, H.; Bi, X.; Bai, Y.; Chen, L.; Ge, D.; Shi, W.; Sun, Y. Polydopamine Nanocapsule: A Theranostic Agent for Photoacoustic Imaging and Chemo-Photothermal Synergistic Therapy. ACS Biomater. Sci. Eng. 2017, 3, 1799-1808. [CrossRef]

20. Yu, X.; Tang, X.; He, J.; Yi, X.; Xu, G.; Tian, L.; Zhou, R.; Zhang, C.; Yang, K. Polydopamine Nanoparticle as a Multifunctional Nanocarrier for Combined Radiophotodynamic Therapy of Cancer. Part. Part. Syst. Charact. 2017, 34, 1600296. [CrossRef]

21. Zhang, J.; Li, J.; Jia, G.; Jiang, Y.; Liu, Q.; Yang, X.; Pan, S. Improving osteogenesis of PLGA/HA porous scaffolds based on dual delivery of BMP-2 and IGF-1 via a polydopamine coating. RSC Adv. 2017, 7, 56732-56742. [CrossRef]

22. Khoshnood, N.; Zamanian, A.; Massoudi, A. Mussel-inspired surface modification of titania nanotubes as a novel drug delivery system. Mater. Sci. Eng. C 2017, 77, 748-754. [CrossRef] [PubMed]

23. Fernandez-Yague, M.A.; Larrañaga, A.; Gladkovskaya, O.; Stanley, A.; Tadayyon, G.; Guo, Y.; Sarasua, J.R.; Tofail, S.A.M.; Zeugolis, D.I.; Pandit, A.; et al. Effects of Polydopamine Functionalization on Boron Nitride Nanotube Dispersion and Cytocompatibility. Bioconjug. Chem. 2015, 26, 2025-2037. [CrossRef] [PubMed]

24. Mu, C.; Zhang, L.; Song, Y.; Chen, X.; Liu, M.; Wang, F.; Hu, X. Modification of carbon nanotubes by a novel biomimetic approach towards the enhancement of the mechanical properties of polyurethane. Polymer 2016, 92, 231-238. [CrossRef]

25. Pekkan, G.; Aktas, A.; Pekkan, K. Comparative radiopacity of bone graft materials. J. Cranio-Maxillofac. Surg. 2012, 40, e1-e4. [CrossRef]

26. Clauss, M.; Trampuz, A.; Borens, O.; Bohner, M.; Ilchmann, T. Biofilm formation on bone grafts and bone graft substitutes: Comparison of different materials by a standard in vitro test and microcalorimetry. Acta Biomater. 2010, 6, 3791-3797. [CrossRef]

27. Zuiderduin, W.C.J.; Westzaan, C.; Huétink, J.; Gaymans, R.J. Toughening of polypropylene with calcium carbonate particles. Polymer 2002, 44, 261-275. [CrossRef]

28. Kim, G.M.; Michler, G.H. Micromechanical deformation processes in toughened and particle filled semicrystalline polymers: Part 2. model representation for micromechanical deformation processes. Polymer 1998, 39, 5699-5703. [CrossRef]

29. Subramanian, A.S.; Tey, J.N.; Zhang, L.; Ng, B.H.; Roy, S.; Wei, J.; Hu, X. 'Matthew' Synergistic bond strengthening in epoxy adhesives using polydopamine/MWCNT hybrids. Polymer 2016, 82, 285-294. [CrossRef]

30. Rodrigues, N.; Benning, M.; Ferreira, A.M.; Dixon, L.; Dalgarno, K. Manufacture and Characterisation of Porous PLA Scaffolds. Procedia CIRP 2016, 49, 33-38. [CrossRef]

31. Ghassemieh, E. Morphology and compression behaviour of biodegradable scaffolds produced by the sintering process. Proc. Inst. Mech. Eng. Part H J. Eng. Med. 2008, 222, 1247-1262. [CrossRef]

32. Deplaine, H.; Acosta-Santamaría, V.A.; Vidaurre, A.; Gómez Ribelles, J.L.; Doblaré, M.; Ochoa, I.; Gallego Ferrer, G. Evolution of the properties of a poly(L-lactic acid) scaffold with double porosity during in vitro degradation in a phosphate-buffered saline solution. J. Appl. Polym. Sci. 2014, 131, 1-10. [CrossRef]

33. Khodaei, M.; Amini, K.; Valanezhad, A. Fabrication and Characterization of Poly Lactic Acid Scaffolds by Fused Deposition Modeling for Bone Tissue Engineering. J. Wuhan Univ. Technol. Mater. Sci. Ed. 2020, 35, 248-251. [CrossRef]

34. Chung, T.-W.; Wang, Y.-Z.; Huang, Y.-Y.; Pan, C.-I.; Wang, S.-S. Poly (e-caprolactone) Grafted With Nano-structured Chitosan Enhances Growth of Human Dermal Fibroblasts. Artif. Organs 2006, 30, 35-41. [CrossRef]

35. Navarro, M.; Engel, E.; Planell, J.A.; Amaral, I.; Barbosa, M.; Ginebra, M.P. Surface characterization and cell response of a PLA/CaP glass biodegradable composite material. J. Biomed. Mater. Res. Part A 2008, 85, 477-486. [CrossRef] 
36. Meaurio, E.; Sanchez-Rexach, E.; Butron, A.; Sarasua, J.R. The conformation of chloramphenicol in the ordered and disordered phases. Spectrochim. Acta Part A Mol. Biomol. Spectrosc. 2019, 211, 383-392. [CrossRef]

37. Ferreira, M.; Rzhepishevska, O.; Grenho, L.; Malheiros, D.; Gonçalves, L.; Almeida, A.J.; Jordão, L.; Ribeiro, I.A.; Ramstedt, M.; Gomes, P.; et al. Levofloxacin-loaded bone cement delivery system: Highly effective against intracellular bacteria and Staphylococcus aureus biofilms. Int. J. Pharm. 2017, 532, 241-248. [CrossRef]

38. Cicuéndez, M.; Doadrio, J.C.; Hernández, A.; Portolés, M.T.; Izquierdo-Barba, I.; Vallet-Regí, M. Multifunctional $\mathrm{pH}$ sensitive 3D scaffolds for treatment and prevention of bone infection. Acta Biomater. 2018, 65, 450-461. [CrossRef]

39. Martin, V.; Ribeiro, I.A.C.; Alves, M.M.; Gonçalves, L.; Almeida, A.J.; Grenho, L.; Fernandes, M.H.; Santos, C.F.; Gomes, P.S.; Bettencourt, A.F. Understanding intracellular trafficking and anti-inflammatory effects of minocycline chitosan-nanoparticles in human gingival fibroblasts for periodontal disease treatment. Int. J. Pharm. 2019, 572, 118821. [CrossRef]

40. Clinical and Laboratory Standards Institute. M02-A12 Performance Standards for Antimicrobial Disk Susceptibility Tests; Approved Standard-Twelfth Edition; Clinical and Laboratory Standards Institute: Wayne, PA, USA, 2015.

(C) 2020 by the authors. Licensee MDPI, Basel, Switzerland. This article is an open access article distributed under the terms and conditions of the Creative Commons Attribution (CC BY) license (http://creativecommons.org/licenses/by/4.0/). 